\title{
Aflatoxin M1 in Pasteurized Market Milk in Korea
}

\author{
Kyu Choon Hwang*, Joo Yea Hwang, Hyoun-Wook Kim¹, and Mi-Hwa Oh ${ }^{1}$ \\ Research and Development Center, IR Laboratory Co. Ltd., Seoul 151-050, Korea \\ ${ }^{l}$ National Institute of Animal Science, RDA, Suwon 441-706, Korea
}

\begin{abstract}
Aflatoxin M1, ingested as aflatoxin B1 via contaminated feedstuff and later converted into, is a major problematic target for milk safety control among the aflatoxin class. Korean government has controlled level of AFM1 in milk at 500 ppt as maximum residue level (MRL), and more recently, government also publicized the proposal for more strict control on fungal toxins about infant and baby foods. In this study the levels of Aflatoxin M1 (AFM1) of 42 marketed milk samples were determined with Enzyme-Linked Immunosorbent Assay (ELISA) to evaluate the status on the contamination of Aflatoxin M1. The evaluated ELISA performances of limit of detection (LOD) and the half maximal inhibitory concentration $\left(\mathrm{IC}_{50}\right)$ were $5 \mathrm{pg} / \mathrm{mL}$ (ppt) and $49 \mathrm{ppt}$, respectively. In all 42 samples, AFM1 appeared above the $5 \mathrm{ppt}$, with the average of $21 \mathrm{ppt}$ and the range of up to $90 \mathrm{ppt}$. Only 3 (7\%) of samples showed the level of contamination above the EU MRL (50 ppt). Although there was incidence of higher level of contamination compared with previous reports, the result of this study requires more intensive study to control of AFM1 in milk and infant foods.
\end{abstract}

Key words: milk, afflatoxin M1, enzyme-linked immunosorbent assay

\section{Introduction}

Aflatoxin M1, among the aflatoxin class, is a major problematic target for milk safety control. It is produced by molds and ingested into animal body through the contaminated feedstuffs during animal breeding. Once ingested by the animal it is rapidly absorbed by the gastrointestinal tract and is transformed from AFB1 into the metabolite AFM1 (Battacone et al., 2003). It has been demonstrated that up to $6 \%$ of the ingested AFB1 is secreted into the milk as AFM1 (Van Egmond and Dragacci, 2001) and, because it is relatively resistant to heat treatments, it is almost entirely retained in pasteurized milk, powdered milk, and infant formula. The hepatotoxicity and carcinogenic effects of AFB1 have been clearly demonstrated and, although lower than those of AFB1, AFM1 has also showed the genotoxicity, carcinogenecity and cytotoxicity (Caloni et al., 2006). As a result of these findings, the International Agency on Research on Cancer (IARC) reclassified AFM1 from group 2B to group 1 human carcinogen (IARC, 2002).

\footnotetext{
*Corresponding author: Kyu Choon Hwang, Research and Development Center, IR Laboratory Co. Ltd., Seoul 151-050, Korea. Tel: 82-2-2082-0271, Fax: 82-2-2082-0274, E-mail: kchwa@ irlaboratory.com
}

Since the year 2003, Korean government has controlled level of AFM1 in milk at $500 \mathrm{ppt}$ as maximum residue level (MRL). However, the MRL level of EU have set for the same as 10 fold lower as 50 ppt and specified for infant and baby food at more strict level as 25 ppt recently (European Commission, 2006). Korean government also recently publicized the proposal of more strict control on fungal toxins for safe infant and baby food products (KFDA, 2011).

In this study, we have tried to investigate the AFM1 contamination in current marketed milk considering that there has been little report on the status about this toxin during a decade.

\section{Materials and Methods}

During the October 2010, 42 samples of pasteurized milk of various brands were collected in supermarkets in Seoul. Samples were aliquoted and freezed for until analysis. There was no significant difference in ELISA results between fresh and frozen milk samples (data not shown).

Determination of AFM1 was done based on a competitive ELISA using the AFM1 ELISA KIT (Euroclone S.p.A. Italy). Preparation of samples was conducted according to the simple modification of instruction of the kit. The kit 
was stored at $2-8^{\circ} \mathrm{C}$ and left $20 \mathrm{~min}$ at room temperature $\left(20-25^{\circ} \mathrm{C}\right)$ before use. Milk samples were thawed from freezer and then centrifuged for $10 \mathrm{~min}$ at $8000 \times g$ at room temperature (Eppendrof, Germany). The upper, creamy layer was removed and aliquot beneath the fat (supernatant without fat) was carefully obtained by micro pipette. The skimmed milk was used directly in the test. The AFM1 standards $(0,5,10,25,50$, and 100 ppt) and test samples were added to 96 wells microtiter plate coated with antiAFM1 antibodies and incubated for $30 \mathrm{~min}$ at room temperature. During incubation, the antibody binding sites were occupied proportionally by the AFMl concentration. After washing step, conjugate AFM1-peroxidase was added to the wells and plate was incubated for $15 \mathrm{~min}$ at room temperature. The unbound conjugate was removed during the washing. Subsequently, developing solution (Chromogen) was added to the wells and incubated for 10 min. The reaction was ended by adding stop solution. The absorbance measurement was made photometrically at 450 $\mathrm{nm}$. The absorbance values obtained for the standards and samples were divided by the absorbance of the first standard and multiply by 100 . Absorbance percentages were taken to the calibration curve performed with standards at different concentration.

Recovery tests were performed to assess the efficacy of ELISA for the analysis of AFM1 in pasteurized milk. AFM1 free raw milk, which confirmed with preliminary screening, was spiked with AFM1 (purchased from Sigma Chemical Co., USA) at concentrations from 5 to 100 ppt. All tests were done in duplicate.

\section{Results and Discussion}

Average $94-108 \%$ of AFM1 added to milk were recovered, and $\mathrm{IC}_{50}$ value was calculated as $49 \mathrm{ppt}$ when determined by ELISA in the range of 5 to 100 ppt (Table 1). The limit of detection, calculated from the variation of AFM1 free milk sample, were found to be $5 \mathrm{ppt}$, showing more higher level in LOD than suggested level of 2 ppt by supplier. However, it was enough sensitive to examine the level of AFM1 below the EU MRL, 50 ppt.

Among the analyzed 42 pasteurized milk samples, $100 \%$ of sample showed detectable residue of AFM1 (Table 2). Although, it was generally safe for consumption regarding the Korean MRL level of 500 ppt, 3 samples showed the level above the EU MRL. The average value of contamination was $21 \mathrm{ppt}$ with the range of 5-90 ppt. Additionally, upper level of contaminated sample of this study was higher than older report of $37 \mathrm{ppt}$ (Kim et al., 2000). This contrast in contamination profiles could be ascribed to any differences in sampling method, in milking season, or in dairy practice through the milk plants compared to decade ago.

In comparison with the recent studies (Kim et al., 2010; Lee et al., 2009), though they used the raw milk at farm level, the average level ( 21 vs. 23-26 ppt) and the ratio of contaminated milk above the 50 ppt were similar (7\% vs. $1 \%, 12 \%)$. This somewhat unexpected result against the general assumption that some of raw milk might have higher level of residue than processed milk in plants due to the dilution effect, could be explained as the difference in sampled source of brands. In those studies, they used

Table 1. Validation data of ELISA for AFM1determination

\begin{tabular}{cccccc}
\hline \hline AFM1Spiked (ppt) & $\begin{array}{c}\text { Number of spiked } \\
\text { samples (n) }\end{array}$ & $\begin{array}{c}\text { Signal at calibration } \\
\text { curve (B/Bo) }\end{array}$ & $\begin{array}{c}\text { AFM1determined } \\
(\mathrm{ppt})\end{array}$ & $\begin{array}{c}\text { Recovery (\%) } \\
\text { Coefficient of varia- } \\
\text { tion (\%) }\end{array}$ & $\begin{array}{c}\text { (\%) } \\
10\end{array}$ \\
\hline 5 & 8 & 0.93 & 5.4 & 108 & 2.6 \\
25 & 8 & 0.86 & 10.2 & 92 & 4.3 \\
50 & 8 & 0.68 & 23.5 & 96 & 3.7 \\
100 & 8 & 0.49 & 48.0 & 96 & 2.4 \\
\hline
\end{tabular}

Table 2. Summary on the survey about AFM1contamination in milk samples in Korea

\begin{tabular}{lcccccc}
\hline \hline \multicolumn{1}{c}{ Sample milk } & $\begin{array}{c}\text { Number of } \\
\text { samples tested (n) }\end{array}$ & $\begin{array}{c}\text { Number of positive } \\
\text { above LOD }\end{array}(\mathrm{n})$ & $\begin{array}{c}\text { Average level of } \\
\text { positive samples (ppt) }\end{array}$ & $\begin{array}{c}\text { Range of positive } \\
\text { samples (ppt) }\end{array}$ & $\begin{array}{c}\text { Number of positive } \\
\text { above } 50 \text { ppt }\end{array}$ & $\begin{array}{c}\text { Comparison with } \\
\text { other study }\end{array}$ \\
\hline Pasteurized milk & 42 & $42\left(5^{1}\right)$ & 21 & $5-90$ & 3 & This Study \\
Pasteurized milk & 70 & $53\left(2^{1}\right)$ & 18 & $2-37$ & ND & Kim et al. $(2000)$ \\
Raw farm milk & 100 & $48\left(20^{1}\right)$ & $23-26$ & ND & 1 & Lee et al. (2009) \\
Raw farm milk & 200 & $159\left(10^{1}\right)$ & ND & ND & 25 & Kim et al. (2010) \\
\hline
\end{tabular}

\footnotetext{
${ }^{1)}$ Limit of detection at ppt
}

ND: not described 
the milk from single dairy company but we used various brands of milk from supermarket.

In this study, we have used commercial ELISA kit as a reliable and rapid tool for screening and a semi-quantitative method in practice. Although Korean legislation for the acceptable residue level for AFM1 is 500 ppt, we found that $7 \%$ of milk is contaminated above the $\mathrm{EU}$ MRL level. Therefore, there is urgent need to extend the surveillance study with more milk samples to manage the risk assessment of Aflatoxin M1 in consumer milk.

\section{Acknowledgements}

This research was supported by 2010 Rural Development Administration (Republic of Korea) research program (PJ007399).

\section{References}

1. Battacone, G., Nudda, A., Cannas, A., Cappio Borlino, A., Bomboi, G., and Pulina, G. (2003) Excretion of AFM1 in milk of dairy ewes treated with different doses of aflatoxin B1. $J$. Dairy Sci. 86, 2667-2675.

2. Caloni, F., Stammati, A., Friggé, G., and De Angelis, I. (2006) Aflatoxin M1 absorption and cytotoxicity on human intestinal in vitro model. Toxicon. 47, 409-415.

3. European Commission (2006) Commission Regulation (EC)
No 1881/2006 of 19 December 2006. Official Journal of the European Union, L364/5-24.

4. International Agency for Research on Cancer (2002) Monograph on the evaluation of carcinogenic risks in humans: Some traditional herbal medicines, some mycotoxins, naphthalene and styrene. IARC, Lyon, France. Vol. 82, pp. 171-274.

5. Korea Food and Drug Administration (KFDA) (2011) Korea Food Code. Visit http://fse.foodnara.go.kr/residue/RS/jsp/menu 02_01_03.jsp?idx=12, Accessed Nov, 5, 2011.

6. Kim, E. K., Shon, D. H., Ryu, D., Park, J. W., Hwang, H. J., and Kim, Y. B. (2000) Occurrence of aflatoxin M1 in Korean dairy products determined by ELISA and HPLC. Food Add. Contamin. 17, 59-64.

7. Kim, H. J., Lee, J. E., Kwak, B. M., Ahn, J. H., and Jeong, S. H. (2010) Occurrence of aflatoxin M1 in raw milk from South Korea winter seasons using an immunoaffinity column and high performance liquid chromatography. J. Food Safe. 30, 804-813.

8. Lee, J. E., Kwak, B. M., Ahn, J. H., and Jeon, T. H. (2009) Occurrence of aflatoxin M1 in raw milk in South Korea using an immunoaffinity column and liquid chromatography. Food Con. 20, 136-138.

9. Van Egmond, H. P. and Dragacci, S. (2001) Liquid chromatographic method for aflatoxin M1 in milk. In: Methods in Molecular Biology, M.W.Trucksess and Pohland A. E. (ed), Humana Press, Totowa (NJ), United States. Vol. 159, pp. 5969.

$\overline{\text { (Received 2011.11.7/Revised 2012.6.11/Accepted 2012.6.12) }}$ 